\title{
Características e rendimento de vagem do feijão-vagem em função de fontes e doses de matéria orgânica.
}

\author{
Gilmara M. Santos; Ademar P. Oliveira; José Algaci L. Silva; Edna U. Alves; Caciana C. Costa \\ UFPB - CCA, C. Postal 02, 58.397-000 Areia - PB. E-mail: ademar@cca.ufpb.br
}

\begin{abstract}
RESUMO
Com o objetivo de avaliar doses e fontes de matéria orgânica na cultura do feijão-vagem, cultivar Macarrão Trepador, instalou-se um experimento em condições de campo no período de julho a novembro de 1998, no Centro de Ciências Agrárias da Universidade Federal da Paraíba. O delineamento experimental empregado foi blocos casualizados, em esquema fatorial 4 x 5 , compreendendo quatro fontes de matéria orgânica (esterco de galinha, esterco bovino, esterco caprino e húmus de minhoca) e cinco doses, sendo $0 ; 5 ; 10 ; 15$ e 20 t/ha de esterco de galinha; e, $0 ; 10 ; 20 ; 30$ e 40 t/ha de esterco bovino, caprino e húmus de minhoca, em quatro repetições. Utilizaramse parcelas com 20 plantas, espaçadas de $1,00 \times 0,50 \mathrm{~m}$. Os resultados indicaram que o comprimento de vagens aumentou linearmente com as doses de estercos de galinha, de bovino e de caprino. O peso médio de vagens foi influenciado apenas pelo esterco de galinha. $\mathrm{O}$ húmus de minhoca não exerceu efeito sobre a característica e a produtividade de vagens. O esterco de galinha na dose de 13,0 t/ha proporcionou rendimento máximo de vagens ( $26,3 \mathrm{t} / \mathrm{ha})$, o esterco bovino na dose de 24,0 t/ha produziu 30,3 t/ha e o esterco caprino, na dose de 16,6 t/ha, produziu 23,0 t/ha. A análise econômica indicou a dose de $11 \mathrm{t} / \mathrm{ha}$ de esterco de galinha e de 23,0 t/ha de esterco bovino, como as mais viáveis economicamente para adubação orgânica no feijão-vagem, resultando num rendimento estimado de 11,3 e 21,2 t/ha de vagens e uma receita prevista de 8.000 e $21.000 \mathrm{~kg} / \mathrm{ha}$ de vagens, respectivamente. Para o esterco caprino, 20 t/ha apresentou saldo um pouco superior à sua ausência, enquanto $10 \mathrm{t} / \mathrm{ha}$ de húmus de minhoca revelou saldo de $\mathrm{R} \$ 2.336,00 /$ ha, porém, inferior à sua ausência. Conclui-se, pois, que nas condições em que foi realizada a presente pesquisa, não é vantajoso o emprego do esterco caprino e do húmus de minhoca como fontes de matéria orgânica para programas de produção de vagens em feijão-vagem.
\end{abstract}

\begin{abstract}
Characteristics and yield of snap-bean pod in function of sources and levels of organic matter.

With the objective of evaluating levels and sources of organic matter in the culture of the snap-bean, Macarrão Trepador cultivar, an experiment in field conditions was setted in the period from July to November 1998, in the Federal University of Paraíba, Brazil. The experimental design was of randomized blocks, in factorial scheme $4 \times 5$, with four sources of organic matter (chicken manure, bovine manure, goat manure and earthworm compost) and five levels $(0,5$, 10,15 and $20 \mathrm{t} / \mathrm{ha}$ of chicken manure and, 0, 10, 20, 30 and $40 \mathrm{t} / \mathrm{ha}$ of bovine manure, goat manure and earthworm compost), in four replications. Plots were of 20 plants, space $1.00 \times 0.50 \mathrm{~m}$. The results indicated that the length of beans increased linearly with the levels of chicken, bovine and goat manure. The average weight of pods was just influenced by chicken manure. The earthworm compost didn't exercise effect on the characteristics and the productivity of pods. The use of $13.0 \mathrm{t} / \mathrm{ha}$ of chicken manure provided maximum yield of pods ( $26.3 \mathrm{t} / \mathrm{ha}$ ), the bovine manure in the level of $24.0 \mathrm{t} / \mathrm{ha}$ produced $30.3 \mathrm{t} / \mathrm{ha}$ and the goat manure in the level of $16.6 \mathrm{t} / \mathrm{ha}$ produced $23.0 \mathrm{t} / \mathrm{ha}$. The economical analysis indicated the use of 11 $\mathrm{t} / \mathrm{ha}$ of chicken manure and $23 \mathrm{t} / \mathrm{ha}$ of bovine manure the most viable sources of organic fertilization in snap-bean, by resulting in a productivity of 11.3 and $21.2 \mathrm{t} / \mathrm{ha}$ of pods and a foreseen yield of 8 and $21 \mathrm{t} / \mathrm{ha}$ of pods, respectively. For the goat manure, the use of 20 $\mathrm{t} / \mathrm{ha}$ revealed to be a little superior compared to its absence, while 10 $\mathrm{t} / \mathrm{ha}$ of earthworm compost showed a balance of $\mathrm{R} \$ 2.336 .00 / \mathrm{ha}$, but inferior to its absence. In the conditions of the present research, the use of goat manure and earthworm compost as organic matter sources is not advantageous for programs of snap bean pods production.
\end{abstract}

\begin{abstract}
A literatura não menciona o emprego de adubos orgânicos na cultura do feijão-vagem. Refere-se apenas à adubação mineral, levando em consideração os teores de fósforo e potássio existentes no solo. As recomendações de fertilização da cultura se baseiam em indicações para o feijão-comum (Viggiano, 1990). Entretanto, o feijãovagem difere do feijão-comum quanto ao porte, área foliar, altura, ciclo, hábito de crescimento e produtividade, principalmente, nas cultivares de crescimento indeterminado.
\end{abstract}

É indiscutível a importância e a necessidade de adubos orgânicos em hortaliças (Kimoto, 1993), tanto na produtividade como na qualidade dos produtos obtidos, especialmente em solos com baixo teor de matéria orgânica, sendo considerados agentes condicionadores do solo, por melhorar as condições de cultivo, através da retenção de água e aumento da disponibilidade de nutrientes em forma assimilável pelas raízes. (Filgueira, 1982; Ingue, 1984).

Quantidades adequadas de esterco de boa qualidade podem suprir as ne- cessidades das plantas em macronutrientes, sendo o potássio, o elemento cujo teor atinge valores mais elevados no solo pelo uso contínuo. O teor desses elementos depende, entretanto, da qualidade e da quantidade de esterco, bem como do tipo de solo (Lund \& Doss, 1980). O esterco de galinha pode suprir parcial ou integralmente as exigências nutricionais do tomateiro, resultando em maiores rendimentos e qualidade de frutos (Silva Júnior \& Vizzoto, 1990). O esterco bovino desempenha papel importante no aumento da produ- 
tividade em diversas hortaliças (Filgueira, 1982; Camargo, 1984; Silva et al., 1989; Seno, 1995; Espínola, 1998). O esterco caprino, apresenta fermentação mais rápida do que o esterco de galinha e bovino, podendo ser utilizado com sucesso na agricultura após um menor período de decomposição (Tibau, 1993); Em algumas hortaliças tem desempenhado papel importante na elevação da produtividade (Leal \& Souza, 1992; Ferreira et al., 1993). O vermicomposto contém nutrientes essenciais às plantas numa forma mais disponível, especialmente o nitrogênio (Hara, 1989), sendo que seu emprego tem proporcionado resultados satisfatórios, na elevação da produtividade de alface e de cenoura (Ricci et al., 1993; Espínola, 1998).

Devido à carência de informações sobre o emprego de matéria orgânica na cultura do feijão-vagem, foi realizado o presente trabalho que objetivou avaliar fontes e doses de matéria orgânica sobre característica e rendimento de vagens.

\section{MATERIAL E MÉTODOS}

Foi instalado um experimento em Latossolo Vermelho-Amarelo, no Centro de Ciências Agrárias da Universidade Federal da Paraíba no município de Areia (PB), entre julho a novembro de 1998. Utilizou-se o delineamento experimental de blocos casualizados em esquema fatorial $5 \times 4$, constituídos de quatro fontes de matéria orgânica (esterco de galinha, húmus de minhoca, esterco bovino e esterco caprino) e cinco doses, sendo $0,5,10,15$ e 20 t/ha de esterco de galinha; e $0,10,20,30$ e $40 \mathrm{t} /$ ha de húmus de minhoca, de esterco bovino e de esterco caprino com quatro repetições.

A análise química do solo indicou as seguinte características: $\mathrm{pH}=6,10$; $\mathrm{P}=92 \mathrm{mg} / \mathrm{dm}^{3} ; \mathrm{K}=105 \mathrm{mg} / \mathrm{dm}^{3} ; \mathrm{Ca}^{+2}$ $=3,10 \mathrm{cmol} / \mathrm{dm}^{3} ; \mathrm{Mg}^{+2}=1,30 \mathrm{cmol} / \mathrm{dm}^{3}$ e matéria orgânica $=9,88 \mathrm{~g} / \mathrm{dm}^{3}$. A caracterização química das fontes de matéria orgânica apresentou os resultados: húmus de minhoca $(\mathrm{P}=5,10 \mathrm{~g} / \mathrm{kg} ; \mathrm{K}=$ $3,31 \mathrm{~g} / \mathrm{kg} ; \mathrm{N}=4,05 \mathrm{~g} / \mathrm{kg}$; matéria orgânica $=103,3 \mathrm{~g} / \mathrm{dm}^{3}$ e relação $\mathrm{C} / \mathrm{N}=21 /$ $1)$, esterco de galinha $(P=6,97 \mathrm{~g} / \mathrm{kg} ; \mathrm{K}$ $=14,36 \mathrm{~g} / \mathrm{kg} ; \mathrm{N}=11,5 \mathrm{~g} / \mathrm{kg}$; matéria orgânica $=265,20 \mathrm{~g} / \mathrm{dm}^{3}$ e relação $\mathrm{C} / \mathrm{N}$ $=13 / 1)$, esterco bovino $(\mathrm{P}=5,2 \mathrm{~g} / \mathrm{kg} ; \mathrm{K}$ $=4,90 \mathrm{~g} / \mathrm{kg} ; \mathrm{N}=8,82 \mathrm{~g} / \mathrm{kg}$; matéria orgânica $=112,07 \mathrm{~g} / \mathrm{dm}^{3}$ e relação $\mathrm{C} / \mathrm{N}=$ $14 / 1)$ e esterco caprino ( $\mathrm{P}=7,2 \mathrm{~g} / \mathrm{kg} ; \mathrm{K}$ $=8,46 \mathrm{~g} / \mathrm{kg} ; \mathrm{N}=7,1 ;$ matéria orgânica $=124,02 \mathrm{~g} / \mathrm{dm}^{3}$ e relação $\mathrm{C} / \mathrm{N}=10 / 1$ ).

O solo foi preparado mediante aração, gradagem, levantamento de leirões e abertura de covas de plantio. A adubação constou apenas do fornecimento das fontes e doses de matéria orgânica 15 dias antes da semeadura. As parcelas constaram de 20 plantas, espaçadas de $1,00 \mathrm{~m}$ entre fileiras e $0,50 \mathrm{~m}$ entre plantas, todas consideradas úteis.

Na semeadura, utilizaram-se quatro sementes por cova da cultivar Macarrão Trepador, a partir de sementes comerciais. Aos 15 dias realizou-se o desbaste, deixando-se uma planta por cova, e a prática de tutoramento pelo sistema de varas cruzadas.

Procurou-se manter as plantas sempre no limpo, por meio de capinas, com auxílio de enxadas para evitar concorrência com plantas daninhas. Foram efetuadas irrigações pelo método de aspersão, no período de ausência de precipitação. Realizou-se controle fitossanitário, por meio da aplicação de Benomyl para controlar mancha de alternaria (Alternaria alternata) ferrugem (Uromyces appendiculatus) e mancha angular (Phaeoisariopsis griseola).

O plantio foi realizado no início de julho. As colheitas, em número de cinco, foram efetuadas semanalmente a partir de 50 dias do plantio. A característica da vagem foi avaliada pelo comprimento e peso médio de vagem, enquanto a produtividade foi obtida pelo somatório da produção das colheitas e transformada em toneladas de vagens/ha.

Os dados obtidos foram submetidos à análise de variância e de regressão polinomial, utilizando-se o programa de computação SAEG (1997).

A partir das equações de segundo grau ajustadas, calculou-se a dose de esterco de galinha e de bovino que proporcionou produtividade máxima econômica. Entretanto, a fim de atenuar os problemas de variação cambial, para as fontes de matéria orgânica que permitiram o cálculo da dose mais econômica, trabalhou-se com uma relação de troca ao invés de moeda corrente, igualandose a derivada segunda às relações entre preços do produto e do insumo (Raij, 1991; Natale et al., 1996), vigentes em Areia-PB, em 1998, buscando-se assim dados mais estáveis. Neste estudo, os valores utilizados para as variáveis vagens e matéria orgânica, foram: $\mathrm{R} \$$ $400,00 /$ t de vagens, $R \$ 30,00 / t$ de esterco bovino e caprino e $\mathrm{R} \$ 120,0 / \mathrm{t}$ de esterco de galinha e húmus de minhoca. Dessa maneira, a 'moeda' utilizada nos cálculos da dose econômica de esterco de galinha e de bovino, foi a própria vagem. A relação de equivalência entre a tonelada de esterco bovino e a tonelada de vagens foi igual a 0,075 e entre a tonelada de esterco de galinha e a tonelada de vagens foi igual a 0,3 ; ressaltando porém que o preço da tonelada da vagem correspondeu ao utilizado pelo produtor e, que essa relação de preços pode variar a cada ano, conforme a demanda e oferta.

\section{RESULTADOS E DISCUSSÃO}

A característica comprimento de vagem foi influenciada pelo esterco de galinha, bovino e caprino, enquanto a característica peso médio de vagem, pelo esterco de galinha.

O comprimento da vagem aumentou linearmente com as doses de esterco de galinha, de bovino e de caprino (Figuras 1 e 2).

A resposta do esterco de galinha para o peso médio de vagem, foi de natureza quadrática (Figura 3). A derivada da equação de regressão revelou a dose de 10 t/ha de esterco de galinha, como a responsável pelo menor peso médio das vagens no feijão-vagem (9,52 g). Em tomateiro, Salek et al. (1981) verificaram elevação no peso médio de frutos empregando o esterco de galinha como fonte de matéria orgânica.

Com exceção do húmus de minhoca, todas as fontes de matéria orgânica influenciaram significativamente o rendimento de vagens nos tratamentos avaliados.

O esterco de galinha apresentou efeito quadrático sobre o rendimento de vagens (Figura 4), com ponto de máximo em 13,0 t/ha, responsável pela produtividade de 26,3 t/ha. Em outras hortaliças, vários trabalhos têm mostrado 


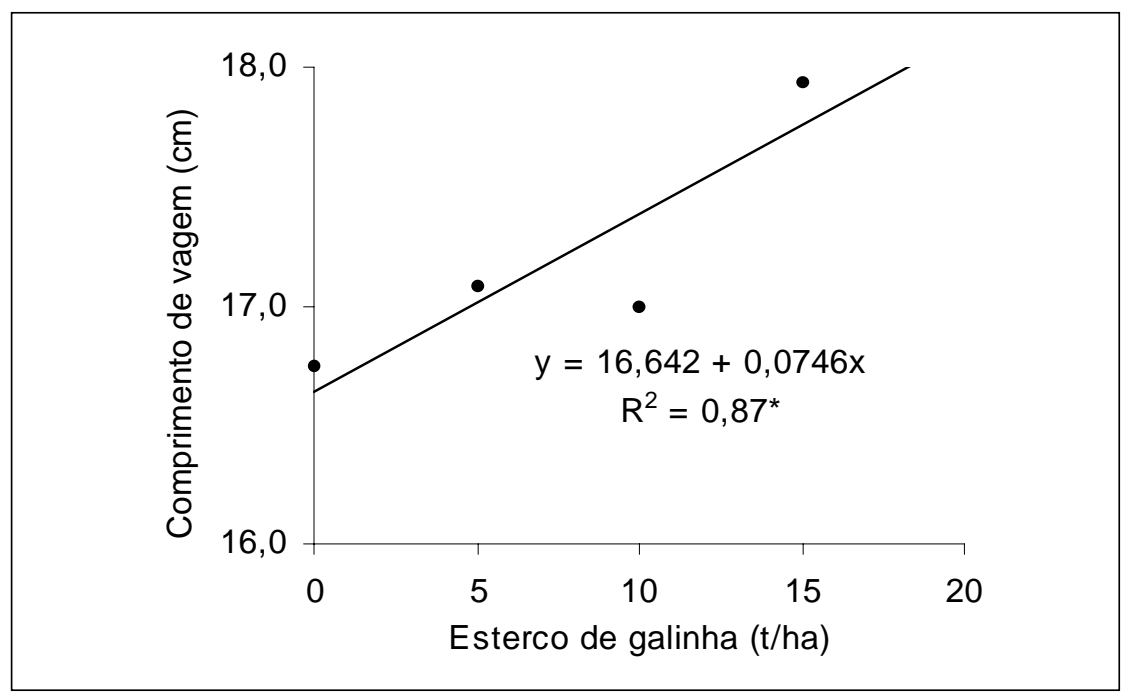

Figura 1. Comprimento de vagem de feijão-vagem, em função de doses de esterco de galinha. Areia, CCA-UFPB, 1998.

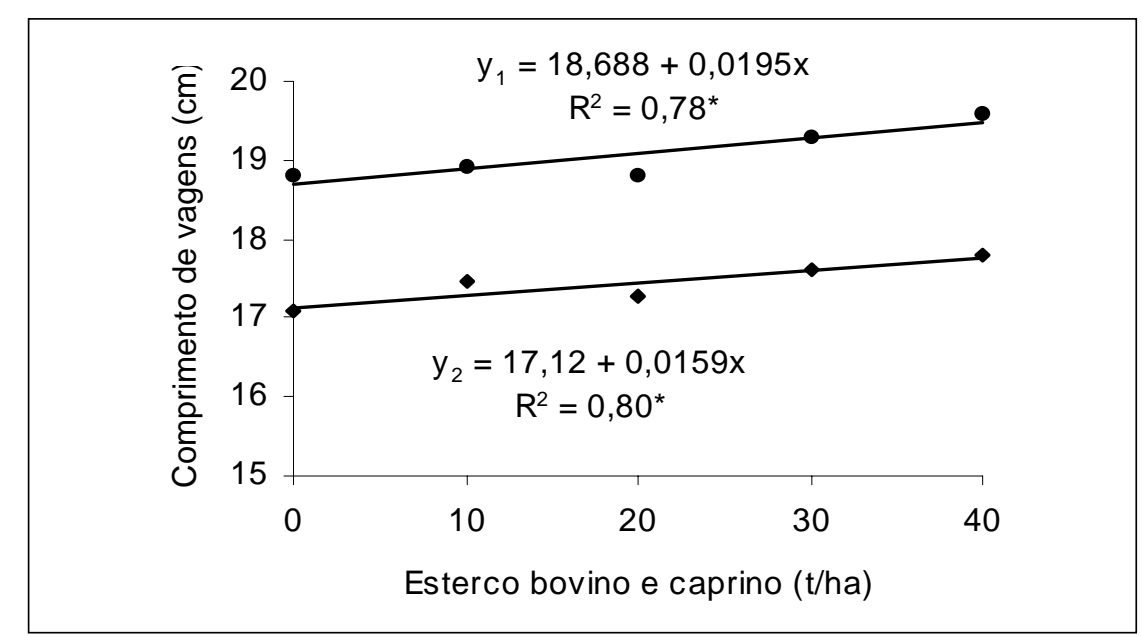

Figura 2. Comprimento de vagem de feijão-vagem em função de doses de esterco bovino $\left(\mathrm{y}_{1}\right)$ e de caprino $\left(\mathrm{y}_{2}\right)$. Areia, CCA-UFPB, 1998.

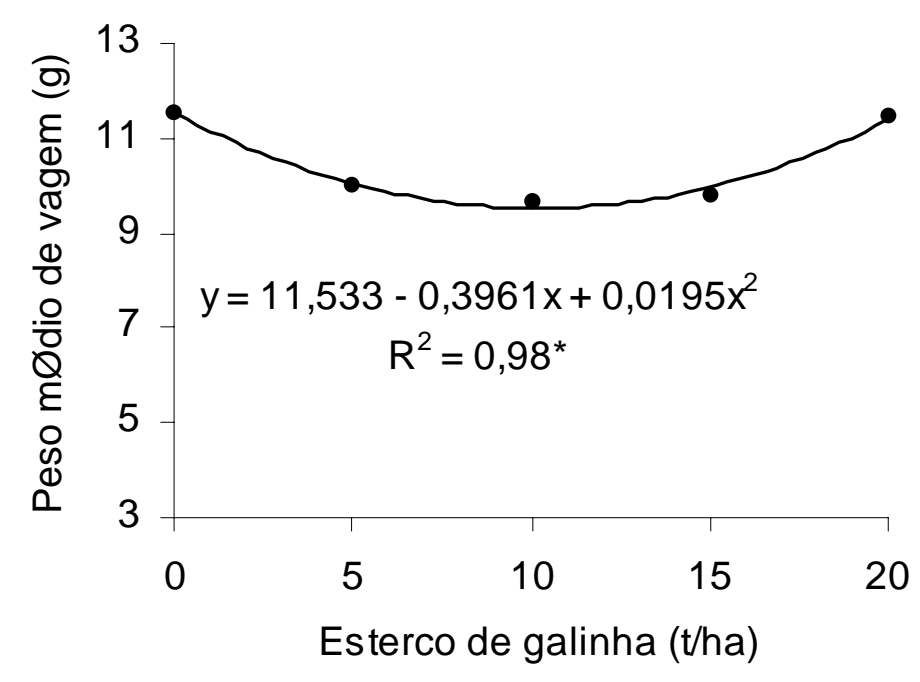

Figura 3. Peso médio de vagem de feijão-vagem, em função de doses de esterco de galinha. Areia, CCA-UFPB, 1998. elevação do rendimento em função da aplicação de esterco de galinha. No tomateiro, Salek et al. (1981) e Ferreira et al. (1993), no alho, Seno et al. (1996), e na cenoura, Souza (1990), obtiveram elevação no rendimento empregando doses variáveis de esterco de galinha. No feijão-vagem, Alves (1999), obteve elevado rendimento de sementes com 20 t/ha de esterco de galinha.

A resposta do esterco bovino sobre o rendimento de vagens foi de natureza quadrática (Figura 5). Pela estimativa da equação da regressão, calculou-se a dose de 24,0 t/ha, como a responsável pelo máximo rendimento de vagens $(30,3 \mathrm{t} /$ ha). Há consenso entre diversos autores da eficiência do esterco bovino em elevar a produção de hortaliças, Em alho, por exemplo, Seno et al. (1995), bem como no tomateiro, conforme Nakagawa \& Conceição (1977), houve aumento na produção dessas hortaliças quando utilizou-se o esterco bovino como fonte de matéria orgânica. Alves (1999), verificou rendimento máximo de sementes com 29 t/ha de esterco bovino. Com relação ao emprego do esterco caprino, a exemplo do esterco de galinha e esterco bovino, os dados ajustaram-se ao modelo quadrático (Figura 6). A dose de 17,0 t/ha de esterco caprino, foi responsável pelo rendimento máximo de vagens (23,0 t/ha). Elevação na produtividade do tomateiro e da alface, com o emprego de esterco caprino como fonte de matéria orgânica, foi retratada de forma positiva por Ferreira et al. (1993) e por Leal \& Souza (1992), respectivamente, com o emprego de $20 \mathrm{t} /$ ha de esterco caprino. Não obstante, elevação no rendimento de sementes no feijão-vagem empregando o esterco caprino como fonte de matéria orgânica, foi verificado por Alves (1999).

A correlação significativa positiva entre o comprimento e o rendimento de vagens $(0,84 * *)$ e o baixo valor verificado para a correlação entre o rendimento e o peso médio de vagens $(0,42 *)$, indicam que o rendimento do feijão-vagem, foi função do comprimento de vagens e não foi influenciado pelo seu peso médio.

Os rendimentos máximos de vagens obtidos pelo uso do esterco de galinha (26,9 t/ha), e de esterco bovino (30,3 t/ ha), superaram a média nacional que, 
segundo Blanco et al. (1997), está em torno de 25,0 t/ha de vagens, em cultivares de feijão-vagem de hábito de crescimento indeterminado. Os benefícios proporcionados pela adição de esterco de galinha e de esterco bovino, possivelmente estejam relacionados ao suplemento de nutrientes de forma equilibrada permitindo ao feijão-vagem a capacidade máxima de produção de vagens, induzida pela sua constituição genética e pela condição do experimento, responsáveis pelos resultados obtidos. Segundo Primavesi (1985), o equilíbrio entre os elementos nutritivos proporcionam maiores produtividades do que maiores quantidades de macronutrientes, isoladamente. Também, acredita-se que os efeitos do esterco de galinha e do esterco bovino sobre a produtividade de vagens, devam-se não somente ao suprimento de nutrientes, mas a melhoria da estrutura do solo e o fornecimento de água, proporcionando melhor aproveitamento dos nutrientes originalmente presentes (Peavy \& Greig, 1972).

A ausência de resposta significativa à adubação com húmus de minhoca, pode ser atribuída à alta quantidade de nutrientes originalmente presentes no solo e às baixas concentrações de $\mathrm{N} \mathrm{e} \mathrm{K}$ na sua composição, embora contenha elevada disponibilidade de matéria orgânica.

Analisando-se economicamente os resultados, a dose mais econômica de esterco de galinha e de esterco bovino foi de 11 e 23,0 t/ha, resultando num rendimento estimado de 26,3 e 30,3 t/ ha de vagens, respectivamente. A receita prevista, devido à aplicação do esterco de galinha e do esterco bovino, pode ser calculada pelo aumento de produção proporcionada pelas doses econômicas, custo do fertilizante e pela receita obtida. Igualando-se a derivada primeira a zero, pôde-se calcular o aumento de produção proporcionado por estas fontes de matéria orgânica. $\mathrm{O}$ esterco de galinha proporcionou um aumento de 11,3 t/ha e o esterco bovino de 21,2 t/ha de vagens. Deduzindo-se o custo de aquisição de 11 toneladas de esterco de galinha (3.300 kg de vagens) e de 23,0 toneladas de esterco bovino ( $1.710 \mathrm{~kg}$ de vagens), obteve-se um receita prevista de 8.000 e $21.000 \mathrm{~kg} / \mathrm{ha}$ de vagens, para

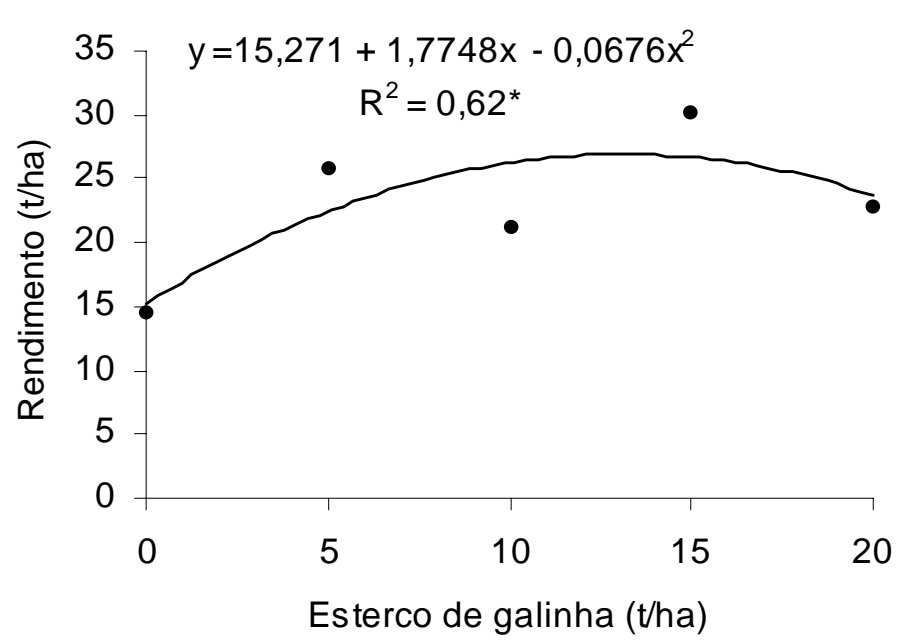

Figura 4. Rendimento do feijão-vagem, em função de doses de esterco de galinha. Areia, CCA-UFPB, 1998.

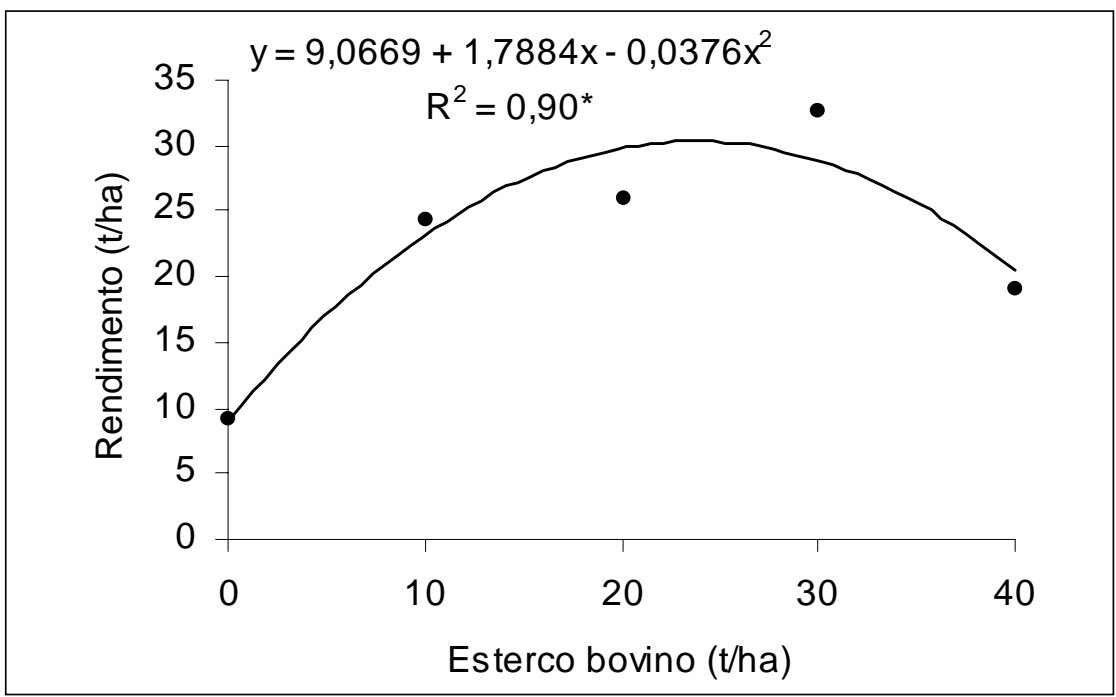

Figura 5. Rendimento do feijão-vagem, em função de doses de esterco bovino. Areia, CCAUFPB, 1998.

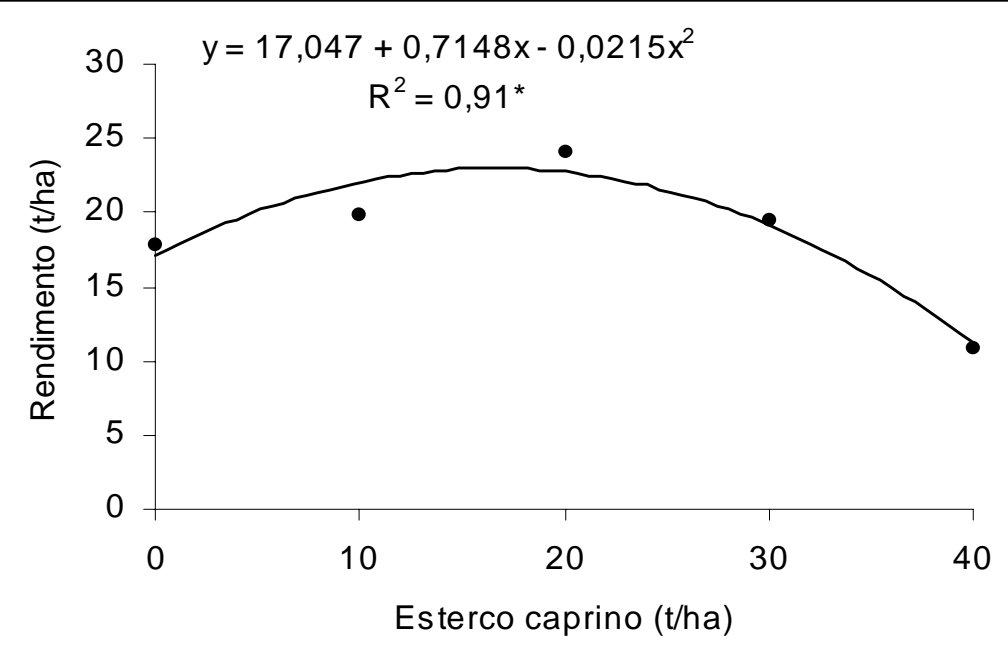

Figura 6. Rendimento do vagens de feijão-vagem, em função de doses de esterco caprino. Areia, CCA-UFPB, 1998 
Tabela 1. Rendimento de vagens de feijão-vagem, renda bruta, custo de aplicação e receita, em função de húmus de minhoca e saldo. Areia, CCA-UFPB, 1999.

\begin{tabular}{|c|c|c|c|c|}
\hline $\begin{array}{c}\text { Esterco } \\
\text { caprino } \\
\text { (t/ha) }\end{array}$ & $\begin{array}{l}\text { Rendimento } \\
(\mathrm{t} / \mathrm{ha})\end{array}$ & $\begin{array}{r}\text { Renda bruta } \\
(\mathrm{R} \$ / \mathrm{ha}=\mathrm{A})\end{array}$ & $\begin{array}{c}\text { Custo de } \\
\text { aquisição } \\
(\mathrm{R} \$ / \text { ha = B) }\end{array}$ & $\begin{array}{c}\text { Saldo } \\
(R \$ / h a=A-B)\end{array}$ \\
\hline 0 & 17,92 & $7.168,00$ & - & $7.168,00$ \\
\hline 10 & 19,85 & $7.940,00$ & 30,00 & $6.740,00$ \\
\hline 20 & 24,08 & $9.632,00$ & 600,00 & $9.032,00$ \\
\hline 30 & 19,54 & $7.816,00$ & 900,00 & $6.916,00$ \\
\hline 40 & 10,80 & $4.320,00$ & $1.200,00$ & $3.120,00$ \\
\hline \multicolumn{5}{|c|}{ Húmus de minhoca (t/ha) } \\
\hline 0 & 18,59 & $7.436,00$ & - & $7.436,00$ \\
\hline 10 & 27,43 & $3.536,00$ & $1.200,00$ & $2.336,00$ \\
\hline 20 & 19,56 & 424,00 & $2.400,00$ & $-1.976,00$ \\
\hline 30 & 16,22 & $-948,00$ & $3.600,00$ & $-2.652,00$ \\
\hline 40 & 26,14 & $3.020,00$ & $4.480,00$ & $1.460,00$ \\
\hline
\end{tabular}

o esterco de galinha e o bovino, respectivamente.

As doses mais econômicas de esterco de galinha e de bovino, estiveram próximas dos valores máximos atingidos pelo rendimento (figuras 4 e 5) e, sob o ponto de vista de rendimento, as doses econômicas de esterco de galinha e de esterco bovino, proporcionaram rendimentos de vagens acima da média nacional, indicando os benefícios do emprego destas fontes de matéria orgânica na produção de vagens no feijão-vagem. Contudo, o esterco bovino por apresentar maior rendimento e a mais elevada receita prevista deve ser recomendado como fonte de matéria orgânica de origem animal num programa de adubação orgânica para esta hortaliça.

Para o esterco caprino, a relação entre esterco e rendimento de vagens, embora tenha ajustado-se a modelo quadrático, apresentou valor abaixo da média nacional, não permitindo o cálculo da sua dose mais econômica, enquanto para o húmus de minhoca não se constatou influência significativa sobre o rendimento. Portanto, estas duas fontes foram avaliadas economicamente pela diferença entre a renda bruta e o custo de aquisição, em moeda corrente (Pereira et al., 1985). Para o esterco caprino, relacionando a renda bruta com o custo dos adubos, pode-se verificar, sob o ponto de vista dos rendimentos, que nenhuma dose apresentou produtividade acima da média nacional e sob o ponto de vista econômico a aplicação de $20 \mathrm{t} /$ ha foi a única que apresentou saldo um pouco superior à sua ausência, enquanto para o húmus de minhoca, as doses de 10 e 40 t/ha, propiciaram rendimentos acima da média nacional (Tabela 1). Sob o ponto de vista econômico, estas doses foram as únicas que propiciaram saldos positivos, com destaque para $10 \mathrm{t} / \mathrm{ha}$, com $\mathrm{R} \$ 2.336,00 /$ ha, porém inferior à ausência de húmus de minhoca. Nas condições em que foi realizado a presente pesquisa, não é vantajoso o emprego do esterco caprino e do húmus de minhoca, em relação à ausência de suas aplicações e ao esterco de galinha e de bovino, caracterizandose como fontes de matéria orgânica não recomendadas para programas de produção de vagens de feijão-vagem.

\section{AGRADECIMENTOS}

Os autores agradecem a professora Sheila Costa de Farias pela correção do Abstract e aos agentes em Agropecuária José Ribeiro Dantas Filho, Francisco de Castro Azevedo, José Barbosa de Souza, Francisco Soares de Brito, Francisco Silva do Nascimento e Expedito de Souza Lima que viabilizaram a execução dos trabalhos de campo.

\section{LITERATURA CITADA}

ALVES, E.U., OLIVEIRA, A.P., GONÇALVES, P.E., COSTA, C.C. Produção e qualidade de sementes de feijão-vagem em função de doses efontes de matéria orgânica: UFPB, 1999. 109 p. (Tese mestrado)
BLANCO, M.C.S.G.; GROPPO, G.A.; TESSARIOLI NETO, J. Feijão-vagem (Phaseolus vulgaris L.) Manual Técnico da Culturas, Campinas (SP), n. 8, p. 63-65, 2a ed., 1997.

CAMARGO, L.S. As hortaliças e seu cultivo. Campinas: Fundação Cargill, p. 28-29, 1984.

ESPÍNOLA, J.E.F. Produção e Qualidade de raizes de Cenoura (Daucus carota L.) cultivada com húmus de minhoca e adubação mineral. Areia: UFPB, 1998. 61 p. (Tese mestrado).

FERREIRA, M.E.; CASTELLANE, P.E.; CRUZ, M.C.P. Nutrição e adubação de hortaliças. Piracicaba - SP: Potafós, 1993. 487 p.

FILGUEIRA, F.A.R. Manual de Olericultura: $\mathrm{Cul}$ tura e Comercialização de Hortaliças. $2^{\mathrm{a}}$ ed. São Paulo, Agronômica Ceres, 1982. 385 p.

HARA, T. Effects of nitrogen, phosphorus and potassium in culture solution on the head yield and free sugar composition of cabbage. Journal of the Japanes Society for Horticultural Science. v. 58, n. 3, p. 595 - 599, 1989.

INGUE, K. Dinâmica da matéria orgânica e seus efeitos nas propriedades do solo. In: Adubação verde no Brasil, Campinas - SP: CARGILL, 1984. p. 232-267.

KIMOTO, T. Nutrição e adubação de repolho, couve-flor e brócoli. In: NUTRIÇÃO E ADUBAÇÃO DE HORTALIÇAS. Jaboticabal, 1983. Anais. Jaboticabal, UNESP., p. 149-178, 1993.

LEAL, F.R.; SOUZA, R.M. Efeitos de diferentes níveis de esterco de caprinos, isolados e combinados com NPK na produção de alface, cv. Babá de Verão. Horticultura Brasileira, Brasília, v. 10, n. 1, p. 58, 1992.

LUND, Z.F.; DOSS, B.D. Residual effects of dairy cattle manure on plant growth and soil properties. Agronomy Journal, v. 72, n. 1, p. 123 -130, 1980.

NAKAGAWA, I.; CONCEIÇÃO, A.D. Efeito de cinco fertilizantes orgânicos na cultura do tomateiro (Lycopersicum exulentrum Mill) estaqueado II. In: EMBRAPA. Tomate: Brasília, 1977. p. 146 (Resumo Informativo)

NATALE, W.; COUTINHO, E.L.M.; BOARETTO, A.; PEREIRA, F.M. Dose mais econômica de adubo nitrogenado para a goiabeira em formação. Horticultura Brasileira, Brasília, v. 14, n. 2, p. 196-199, 1996.

PEAVY, W.S.E.; GREIG, J.K. Organic and mineral fertilizers compared by yield, quality and composition of spinach. Journal of American Society for Horticultural Science, v. 97, p. 718 -723, 1972.

PEREIRA, E.B.; CARDOSO, A.A.; VIEIRA, C.; LOURES, E.G.; KUGIKARI, Y. Viabilidade econômica do composto orgânico na cultura do feijão. Cariacica-ES: EMCAPA, junho 1985. 4 p. (Comunicado técnico).

PRIMAVESI, A. Manejo ecológico do solo: a agricultura em regiões tropicais. São Paulo, editora Nobel, 1985, $541 \mathrm{p}$.

RAIJ, B. VAN. Fertilidade do solo e adubação. Piracicaba: Ceres/Potafós, 1991. 343 p.

RICCI, M.S.F. Crescimento e teores de nutrientes em cultivares de alface (Lactuca sativa $\mathrm{L}$.) adubados com vermicomposto. Viçosa: UFV, 1993. 48 p. (Dissertação mestrado). 
SAEG - Sistema para análise estatística, versão 4.2. Fundação Artur Bernardes, Viçosa-MG, 1997.

SALEK, R.C.; ALMEIDA, D.L.; RIBEIRO, M.I.S.D. Efeito do esterco de galinha e sua associação com fertilizantes sobre a produção do tomateiro no município de Teresópolis $-R J$. Niterói, PESAGRO - Rio, 1981. 3 p. (Comunicado Técnico, 70).

SENO, S.; SALIBA, G.G.; PAULA, F.J. Efeito de doses de fósforo e esterco de galinha na produção do alho (Allium Sativul L). Científica, São Paulo, v. 24, n. 1, p. 127 - 133, 1996.
SENO, S.; SALIBA, G.G.; PAULA, F.J. Utilização de fósforo e esterco de curral na cultura do alho. Horticultura Brasileira, Brasília, v. 13, n. 2, p. 196 - 199, 1995.

SILVA JÚNIOR, A.A.; VIZZOTTO, V.J. Efeito da adubação mineral e orgânica sobre a produtividade e tamanho de fruto de tomate (Lycopersicum esculentum Mill.) Horticultura Brasileira, Brasília, v. 8, n. 1, p. 17-19, 1990.

SILVA, R.M.; BRUNO, G.B.; LIMA, E.D.P.A.; LIMA, C.A.A. Efeito de diferentes fontes de matéria orgânica na cultura do tomateiro (Lycopersicum esculentum Mill.),. Agropecuária Técnica, Areia, v. 10, n. 1-2, p. 36-47, 1989.
SOUZA, A.P. Efeitos de diferentes fontes de adubação orgânicos sobre a produtividade de cenoura (Daucus carota L.) Areia: UFPB, 1990. 74 p. (Monografia graduação).

TIBAU, A.O. Matéria orgânica e fertilidade do solo. São Paulo: Editora Nobel, 1983. 220 p.

VIGGIANO, J. Produção de Sementes de feijãovagem. In: CASTELLANE, P. D. NICOLOSI, W.M, HASEGAWA, M., coord. Produção de sementes de hortaliças. Jaboticabal-SP: Faculdade de Ciências Agrárias e Veterinárias/ Fundação de Estudos e Pesquisas em Agronomia, Medicina Veterinária e Zootecnia, 1990, p.127140. 